\title{
Exploring School Counselor Advocacy in the Career Development of Undocumented Latino Youth
}

\author{
Cassandra A. Storlie \\ Kent State University
}

\begin{abstract}
School counselors working on career development objectives with undocumented Latino youth have unique challenges that can inform and improve advocacy efforts within the counseling profession. With approximately two million undocumented Latino students in the U.S. public education system (Passel, 2006; Passel \& Cohn, 2011), school counselors are faced with unique challenges in providing and advocating for career services to this marginalized group. This qualitative study explored the experiences of 16 school counselors providing career counseling to undocumented Latino students within six states with the highest populations of undocumented Latinos. Using grounded theory methodology (Patton, 2002, Corbin \& Strauss, 2008) results generated salient themes in how school counselors understand the barriers facing undocumented Latino youth and provided important insights into how the school counseling profession can improve advocacy for this population.
\end{abstract}

Keywords: undocumented Latinos, school counseling, career

In the United States, there are 38 million immigrants, with approximately 11.2 million considered undocumented (Passel \& Cohn, 2011; Gonzales, 2009). Between 1.8 and two million undocumented immigrants are school aged Latino students (Passel, 2006; Passel \& Cohn, 2011). Many undocumented Latino youth entered this country as children, having no choice but to follow their parents' direction in crossing the U.S. border in an unauthorized fashion. As these youth assimilate, they begin to recognize that their lack of citizenship affirms they do not have the same opportunities as their American counterparts (Gildersleeve, Rumman \& Mondragon, 2010). As a result, little is understood about unconventional career development trajectory for undocumented Latino youth. Yet, school counselors and student affairs professionals are often the first point of contact to help facilitate a future career path (Ortiz \& Hinojosa, 2010).

According to the American School Counseling Association (ASCA; 2014), through "leadership, 
advocacy, and collaboration, professional school counselors promote equity and access to rigorous educational experiences for all students" (p.1). The ASCA Ethical Guidelines further specify advocacy responsibilities that address issues of "immigration-ism" and "immigration status" [E.2.b and E.2.c]. As advocates, school counselors strongly influence the career trajectory of undocumented Latino youth in American school systems by nature of their role (Ortiz \& Hinojosa, 2010). However, school counselors working on career development objectives with undocumented Latino youth have unique challenges that can inform and improve advocacy efforts within the counseling profession. Undocumented Latino youth have a dismal career outlook due to strong and realistic fears of deportation, limitations in obtaining employment, and holding different values from the majority culture (Storlie \& Jach, 2012). College aspirations are frequently not an option due to limited financial resources (Drachman, 2006; Ortiz \& Hinojosa, 2010) and unjust federal and state legislative acts. Previously, we issued a call to action that all school counselors actively support the needs of undocumented Latino students due to their marginalization within the American school system (Storlie \& Jach, 2012; Storlie, 2015). This qualitative study provides a stronger understanding of the unique experiences school counselors encounter when providing career counseling to undocumented Latino youth and provides important insights to promoting social justice and advocacy on behalf of this population.

\section{Understanding the Worldview of Undocumented Latino Youth}

A variety of legislative efforts have been proposed to advocate on behalf of undocumented youth in the U.S. Federally, the Development, Relief, and Education for Alien Minors (DREAM) Act has been proposed, but has failed to become law (Dream Act Portal, 2012). In response to the needs of undocumented youth, individual states have passed their own versions of the DREAM Act by providing access to in-state college tuition rates to those undocumented youth able to attend college. Moreover, executive orders have been announced to address issues of immigration in the U.S. such as 1) Deferred Action for Childhood Arrivals (DACA) Program; 2) Deferred action for parents of U.S. citizens and lawful permanent residents; 3) Provisional waivers of unlawful presence; 4) Modernize, improve and clarify immigrant and nonimmigrant programs to grow our economy and create jobs; and, 5) Promote the naturalization process (United States Citizenship and Immigration Services [USCIS], 2014). Despite these positive steps, barriers for long term career options persist for undocumented Latino youth, resulting in a unique career counseling challenge for 21 st Century school counselors.

Despite the executive actions on immigration, anxieties about deportation are intense for undocumented Latino youth across this country. Deportation orders for high school and college students in California, Florida, New Jersey, New Mexico and Washington continue to influence a perception of fear among undocumented students (Abrego \& Gonzales, 2010). Furthermore, undocumented Latino students do not have the "cultural capital" in which they know someone who has navigated the educational pathways and may have trouble transitioning to the American educational system (Oldfield, 2007). 
Of all the professionals associated with the U.S. school system, school counselors are best positioned to ease this academic transition and support undocumented Latino youth by nature of their roles as advocates. School counselors have become social justice advocates for undocumented youth through implementing group counseling sessions (Chen, Budianto \& Wong, 2010) and strong therapeutic relationships enhance the optimism and perseverance among undocumented Latino youth (Perez, Espinoza, Ramos, Coronado, \& Cortes, 2009). Emotional and psychological hardships are common for undocumented Latino youth in contemporary society (Storlie \& Jach, 2012). The migration transition can be an extremely traumatic experience for a child (Perez et al., 2009) and confusion and unresolved grief can result from the loss of close friendships and family members. The transition to the U.S. can cause multiple emotional and adjustment issues and require counseling professionals to use trauma informed practices, an urgent need in many public schools.

U.S. schools and teachers, in general, have not been equipped to manage high numbers of Spanish speaking students (Arredondo, Gallardo-Cooper, Delgado-Romero \& Zapata, 2014). Although it is known that language is directly related to Latino ethnicity and culture (Guyll et al., 2010; Sox, 2009), nine southern states have passed bills identifying English as the official language (Crawford, 2004), making it increasingly difficult for undocumented Latino youth (and other Spanish speaking students) to succeed in the American classroom. Moreover, counseling conducted in a language other than one's native language can lead to alienation or difficulty in establishing trust (Arredondo et al., 2014). Adjustment to an individualistic American culture, learning the English language, living in crowded environments and changing role expectations within the family system (Perez et al., 2009) are all additional challenges facing undocumented Latino youth. Depending on the age when the migration occurred, these youth may also be going through physiological and developmental changes; further complicating an increased time of confusion, isolation, fear and uncertainty (Storlie \& Jach, 2012).

Within the worldview of undocumented Latino youth, there may be pressure to contribute financially to their families once they reach a certain age. Due to the high levels of poverty affecting this population, undocumented Latino youth may seek out employment to fiscally provide for their family members, often preventing them from pursuing higher education or advanced skills training. Obstacles can surface when there is competition between family obligations and requirements of the school system. Research conducted by Dotson-Blake, Foster and Gressard (2009), identified that the conflict between school and family demands often result in "dissonance and disequilibrium within the family" (p. 233).

Despite the unique and complicated barriers facing undocumented Latino youth, school counselors are trained to support career development of all school children in these uncertain times. Yet, Constantine, Erickson, Banks and Timberlake (1998) found that minority students receive less career counseling than non-minority students. These implications further decrease the opportunity for career services for children who would otherwise be pushed into a vocational environment of labor work, earnings below minimum wage, and have "no prospects of mobility" (Jefferies, 2008, p. 249). There is limited counseling research that addresses the complex issues of undocumented Latino youth in 
school settings, particularly on the issues of career development and the implications for advocacy. As such, the following research question guided this study: How do national board certified school counselors conduct career counseling with undocumented Latino youth in states with the highest numbers of undocumented Latinos?

\section{Methods}

\section{Participants}

Upon approval from the Institutional Review Board, participants, certified by the National Board of Professional Teaching Standards (NBPTS), were recruited from the NBPTS public online directory of school counselors. School counselors from the ten states that have the highest populations of undocumented Latino immigrants were purposefully recruited to better ensure experiences in working with undocumented Latino youth. Sixteen national board certified school counselors, 14 women and two men, participated in this study. School counselors certified by NBPTS were recruited for this study because of their advanced training in career and multicultural counseling beyond a master's degree, and their dedication to culturally responsive training (NBPTS, 2002).

Pseudonyms were used to protect the identity of these participants. Participants were from the states of California (Dora), Illinois (Mae, Jamie, Ed, Cathy, Chuck, and Amy), Texas (Tammy), Virginia (Melanie, Erika, and Riley), North Carolina (Olivia and Rachel), and Florida (Mary, Candy, and Tricia). Participants self-identified as Caucasian or White $(n=14)$, African American $(n=1)$, and Latino(a) or Hispanic $(n=1)$ with a mean age of 43.9 years $(S D=8.32)$ and a range from age 30 to 58. Participants had a mean of 15.31 years working as school counselors $(S D=6.12)$ and a mean of 4.19 years being certified by the NBPTS (SD=2.10). Ten participants worked in a high school setting and three participants worked in an elementary school. One participant worked as a middle school counselor. One participant worked in both middle and high school settings and one participant worked at the elementary, middle and high school settings as a school counselor. The counselor to student ratio in these counselors' places of employment ranged from 1:207 to 1:900, with a mean of 1:450 (SD=179.05). All participants, with the exception of the Hispanic school counselor, provided counseling services to students in English. The Hispanic school counselor in this study was bilingual and provided counseling to English Language Learners in Spanish.

\section{Procedures}

Upon agreement to the consent form, participants were provided an open-ended survey via email that obtained demographic information and assessed current school counseling practices within their academic setting and interactions with undocumented Latino students. Participants who identified limited interactions with undocumented Latino youth were excluded from participating in the study. After collecting data from the open-ended survey, in-depth, semi-structured interviews were conducted with participants via telephone, email, and Skype. Interviews were completed by the 
author in a semi-structured fashion in order to give flexibility (Drew, Hardman, \& Hosp, 2011; Patton, 2002) and allowed for a rich, thick description of the experience of career counseling and advocacy

efforts with undocumented Latino youth. Sample questions included: 1) Explain the ways in which you advocate and prepare undocumented Latino youth for future careers; 2) What are the unique challenges in the career development of undocumented Latino students in comparison to their documented peers?

Each interview lasted approximately one hour. One interview was completed via Skype, three interviews were conducted via email and 12 interviews were conducted by telephone. In a manner to ensure objectivity, this author used a reflective journal throughout the interview and coding process. Follow up interviews were used in order to clarify or deepen responses to the original interview questions (Patton, 2002) with those participants who chose to complete the interview via email. Data, such as documents, books, films and articles encompassing recent legislative acts on immigration and undocumented Latinos were also utilized for saturation of the topic.

\section{Researcher as Human Instrument}

With qualitative methodology, it is recommended that information about the researcher is provided in order to provide transparency and credibility (Patton, 2002). This researcher is a Mexican-American, assistant professor in a counselor education and supervision program who has had advanced training in qualitative methodology at the doctoral level. Personally, this researcher has familial ties to many undocumented Latinos. As a granddaughter, step-daughter and cousin to individuals who had once been undocumented Latino youth, this researcher has witnessed the social and political barriers that have impacted the career development of these family members. Consequently, it was hoped that this researcher's personal and professional experiences with undocumented Latinos enhanced the data collection and analysis through the research process.

\section{Data Analysis}

After completing transcription, participants were contacted via e-mail for member-checking (Patton, 2002) to clarify the meaning of their responses and to solicit additional information or comments. The analytic framework for organizing the qualitative data was based on the use of a social constructive lens (Patton) to allow for sensitivity of the data in a fluid fashion, accounting for an understanding that participants construct their own reality based on their environment and surroundings.

Data was analyzed through searching for descriptive findings and themes (Patton, 2002). The first classification step incorporated an inductive approach to open coding, in which examination of all transcribed interviews, field notes, and interview and data documentation were completed. This step included identifying patterns and processes within the data. Selective coding was then completed on all data collected. Within this process, open codes were combined to develop a restructured understanding of experiences among the participants. The individually coded data was then 
examined to develop axial coding across all formats (interview, documents, etc.). Through the axial coding process, deductive analysis was used to postulate a hypothesis about the relationships among notions and concepts (Corbin \& Strauss, 2008; Patton). Two peer reviewers were utilized to review all raw data and assigned coding. Each peer reviewer provided this author with objective insights to consider when developing the primary themes.

\section{Results}

The analyzed data resulted in 20 open codes involving categorical themes, seven selective codes (primary themes) including patterns and processes and three axial codes that included overarching relationships within the data. Results below will discuss the primary themes that emerged from the data.

\section{Understanding the Impact of Culture}

Participants identified multiple occasions in which the values of family and tradition among undocumented Latino students superseded educational obligations. That is to say, participants recognized that undocumented Latino students placed priority on the collective good of their families, over their individual needs and desires. Participants expressed that undocumented Latino youth were often working, in addition to attending school to help with family living expenses. Jamie, a school counselor from Illinois, stated: "They want to get a job so they can help their families." Cathy also verbalized her perceptions of how culture and family influence the desire for undocumented Latino students to work instead of go to school. Cathy stated, "They have family members they need to help. They feel responsible for helping out the family financially and they don't know how they are going to do that."

Participants reported their understanding of the cultural impact of students' undocumented status, and noted a predominance of fear. Participants witnessed the fear, hesitation, and a lack of trust among undocumented Latino students at their respective schools. Ed identified, "More than most, undocumented Latino students tend to be very guarded about what they share in their personal life or in their home life." Candy commented, "You try to impress upon them that we [school counselors] are not immigration. We are not going to turn them in. But they don't trust us." Participants also discussed how this fear permeated into parents and families of undocumented Latino students. Amy reported, "The parents can also be a barrier because they are afraid of school authority. They are often afraid that the school officials might report them to the government."

Even when participants had access to interpreters or materials available in Spanish, participants reported commonly having poor home-school communication. Tricia identified, "I have a large population of students that come without knowing how to speak English. This makes it very difficult to graduate and impossible to enter college straight out of high school." According to participants, career guidance lessons often took place in classes designed especially for English Language Learners 
(ELLs), in which the teacher (not a counselor) provided the lesson. However, Cathy, the only Latina and bilingual participant, expressed good communication with undocumented Latino students and their families, along with ease at developing rapport.

\section{Recognizing the Impact of Socioeconomics}

Participants witnessed considerable struggles facing undocumented Latino students who were also victims of poverty and homelessness. Erika reported, "You know, I go and do home visits and see families and see multiple families in a one bedroom apartment, sleeping with blankets and sitting on boxes." Mary stated, "And I went to the house and there was like six mattresses in the living room. And a crib." Participants reported commonly working with homeless students who were also undocumented. Amy stated she linked homeless undocumented Latino students with resources to basic needs, such as medical, dental, food, and shelter when possible. Participants also recognized that the impact of working with impoverished undocumented Latino students also meant confronting issues of gangs and violence.

Participants, in their roles as school counselors, indirectly perceived how gangs and violence impacted the lives of undocumented Latino students. Participants reported hearing stories about shootings and violence during migration to the U.S. Amy recalled: "I had one girl tell me she had people die all around her as she was being smuggled across the border and that was very traumatic to her." Tammy also described, "A lot of them have come over with coyotes and they have seen awful things and they have had awful things done to them." Likewise, participants reported that undocumented Latino students at their schools were often targeted for gangs and experienced pressure to succumb to a life of crime. Mae reported, "You know, there is a lot of pressure and the gangs are really successful in some of these low income housing apartments because the kids are looking for a place to belong and for someone to have fun with." In addition to taking action to prevent gang involvement, participants further expressed frustration in trying to get teachers in their schools to understand the impact of poverty on this population. Two participants elaborated on witnessing prejudicial behavior displayed by school personnel toward undocumented Latino students. Riley stated, "Staff need to be educated on how to work with all students."

In addition to the susceptibility to violence and crime, participants commented that finding funding for undocumented students who were able to enroll in college was an enormous challenge. Cathy explained her frustrations stating, "They are not able to access various types of funding or those types of programs [college bound]." Participants verbalized that finding funds for college was often a school counselor's greatest challenge in providing career related services to this population, particularly due to the lack of accessible resources to attend post-secondary training.

\section{Challenging Legislative Barriers}

Participants working with undocumented Latino youth frequently experienced legislative challenges relating to the absence of a valid Social Security number. Tammy reported, "Everybody tells you just fill out a FAFSA. You know, get your financial aid or whatever. But if you are undocumented, then they 
are like - wait, this doesn't really work for me." Even with some progressive in-state legislative action, school counselors found themselves frustrated in finding support for their undocumented students in college. Dora reported, "In California, we have a law that was just passed to get Pell Grant aid from California. But that still doesn't qualify [undocumented Latino students] for FAFSA." Participants struggled with providing conventional career counseling with these students, particularly due to legislative barriers. Participants recognized that legal employment and the ability to enter into a sustainable career was not possible for undocumented Latino students without a Social Security number. Some participants verbalized working jointly with students to advocate on different avenues of pursuing U.S. citizenship.

Many participants voiced their perception that the largest overall barrier to success for undocumented Latino students involved current immigration law. Melanie conveyed, "It's the laws that seem to be the barrier. If they weren't there then we could talk about going to college and the affordability of going to college just like everybody else." Multiple participants reported counseling students about fears regarding the deportation of parents and family members, and also supported them by writing immigration letters of support. Participants reported poor preparation in understanding the limitations set by immigration law and difficulty in differentiating state versus federal laws on the DREAM Act. Even with DACA, participants expressed witnessing ample hopelessness in this marginalized population. Participants discussed their challenges in providing career services in light of uncertain and unstable legislation. Dora stated, "The biggest challenge is providing hope for kids... because you feel so hopeless. As you get closer to senior year...they think they don't have any options." One participant reflected on her work with an undocumented Latino youth who attempted suicide several times due to the hopelessness that resulted from legislative barriers. All participants discussed their challenge of providing hope to a population that continues to feel hopeless.

\section{Use Career Counseling Theories?}

Although participants clearly identified the unique needs of undocumented Latino students, the majority of participants reported treating all students the same when providing career counseling services. Frankly stated by Rachel, "It's the same approach [to career counseling undocumented Latino students]. It's just that the end result might be different." Riley and Jamie discussed using the World of Work and John Holland's model, yet the other 14 participants did not indicate that they used career counseling theories in their practice. Chuck commented, "The last time any school counselor thought about career counseling theories was when they studied for the last test they took on the subject." Many of the career assessments administered by participants were mandated by state or county education laws and were not chosen specifically by participants to meet the needs of their respective populations.

According to participants, the career counseling approaches that appeared to benefit their undocumented Latino students were conducted in a group setting. Candy focused her advocacy efforts on career guidance in her ELL classes. Ed reported focusing primarily on getting undocumented Latino students through high school. He stated, "It doesn't matter if you are documented or not, if you don't have that diploma - most of the doors are going to be shut off to 
you."

\section{Proactive Advocacy Efforts}

Participants discussed the desire to be preventative in their approaches with undocumented Latino students instead of being reactive, particularly when cognizant of an undocumented status. Participants stated that the lack of any streamlined manner to identify undocumented Latino students prevents them from being proactive to make informed decisions on how to best help this population. Melanie described: "It's kind of like Don't Ask, Don't Tell." Jamie reported, "I don't push the issue. If they feel comfortable telling me then that's fine. But you know: Who's undocumented? Raise your hand. No, we don't do that. It's just a waiting process for us." Without a unified method of identifying undocumented Latino students, some participants voiced a lack of direction as to how to best advocate to meet the needs of this population.

However, participants reported providing outreach, advocacy and support to undocumented Latino students outside of the normal working day. Five participants reported multiple incidents of outreach and support to undocumented Latino students and their families. Participants verbalized educating themselves about immigration laws in order to advocate for the rights of undocumented Latino students. Participants also discussed how they advocated for students to obtain U.S. citizenship by writing letters to immigration attorneys. Tammy stated, "At our school, we have a little bit of a reputation of doing things under the radar. And our principal would be like, you know - just write the letter and help them." Yet, participants did not discuss outreach and advocacy efforts on a mesosystem or macrosystem level, such as lobbying for the rights of undocumented Latino students or developing grass roots efforts to address the complex needs of this population.

\section{It's All About the Relationship}

Participants developed rapport with undocumented Latino students at their respective schools by demonstrating openness to understanding the marginalization and oppressive experiences facing undocumented Latino students. Rachel described, "They talk to me about their fears of being deported and tell me stories of people they know who have been deported." Some participants, newer to their role as a school counselor, voiced difficulty in establishing rapport with some undocumented Latino youth. Participants who had been in their school counseling position for many years reported developing a reputation of trust among students and parents who were undocumented and Latino, and further expressed a smooth experience in developing rapport and establishing relationships.

Cathy, the only Latina participant, reported her cultural background as an asset to the therapeutic relationship. She stated, "I have a very good rapport with all the parents. Especially our undocumented students." Many participants discussed their abilities to connect with undocumented Latino students through the use of another school professional with a Latino background. In addition, most Caucasian participants reported their understanding of the impact of cross cultural challenges with undocumented Latino students and were open to alternative ways of developing rapport. Although 
levels of cultural awareness and cultural identity development among participants were not assessed in this study, participants collectively struggled to provide hope in counseling sessions to undocumented Latino students.

\section{Discussion}

The purpose of this qualitative study was to build a stronger understanding of the unique experiences school counselors encounter when career counseling undocumented Latino students and to explicitly call for an increase in participation, training, and responsibility of school counselors on behalf of undocumented students. Participants provided data that represented an individualistic, cultural perspective that focused on individual empowerment of undocumented Latino students. Yet, undocumented Latino students perceive a collectivistic worldview and a dominance of family unity (Santiago-Rivera, Arredondo, \& Gallard-Cooper, 2002; Arredondo et al., 2014). Although participants voiced concern about undocumented Latino students obtaining lower level jobs to benefit the whole family, versus taking steps toward obtaining a degree in higher education, many failed to understand how a collectivistic worldview (Santiago-Rivera et al.) shapes the perception of many undocumented Latino students who are challenged to adapt to the values of the U.S. school system.

Although some undocumented Latino students may have adapted an individualistic worldview (Storlie \& Jach, 2012), differences in worldviews between participants and undocumented Latino students may have impacted the therapeutic relationship and openness about an undocumented status (Guyll, Madon, Prieto \& Scherr, 2010). Moreover, there is much advantage to communication materials in one's first language (Sox, 2009; Arredondo et al., 2014) and participants verbalized continuous challenges to effectively communicate counseling topics with undocumented Latino students and their families. The use of one's native language is critical in counseling for enhancing the trust, rapport and relationships (Arredondo et al.), specifically among undocumented students and families. This aligns with the importance of continued recruitment of bilingual counselors (SmithAdcock, Daniels, Lee, Villalba \& Indelicato 2006; Villalba, 2007) among districts with high numbers of undocumented Latino youth.

There is an overrepresentation of students of color in poverty (Griffin \& Steen, 2011; Henry, Merten, Plunkett, \& Sands, 2008) and many participants provided home visits and advocacy services to link undocumented Latino youth with basic health care services, typically functioning outside of the traditional role of a school counselor. Participants also discussed internships, scholarships, higher education grants, and legal employment that were inaccessible to undocumented Latino students. The lack of these accessible resources may continue to steer undocumented Latino youth towards gang affiliation, as they uncover little opportunity for future success in the U.S. Based on these interviews, the financial hurdles to pay for college appeared insurmountable to participants and undocumented Latino students. Participants recognized that many colleges required out of state tuition for undocumented Latino students, coinciding with Gonzales's (2010) findings that out of state tuition is often the norm required if undocumented students are admitted to college. Some 
participants were internally motivated to seek out information about the acceptance of undocumented students in their respective states. Participants also discussed counseling and career guidance approaches that were successful with undocumented Latino students, such as working with students within a cohort model and in group settings.

Participants reported poor preparation in understanding the limitations set by immigration law and difficulty in differentiating state versus federal laws on the DREAM Act. With immigration laws and legislative acts creating an incalculable barrier for undocumented Latino students, participants also counseled students about the deportation of parents and family members, and wrote support letters for immigration attorneys. Participants witnessed ample hopelessness in this marginalized population.

The barriers facing undocumented Latino students have been shown to result in lower perceptions of self-esteem and self-confidence (Telzer \& Garcia, 2009). Additionally, undocumented Latino students who have witnessed Immigration and Customs Enforcement (ICE) raids have been found to demonstrate extreme behavioral changes such as anxiety, depression, fear, anger and changes in eating and sleeping patterns (Casas \& Cabrera, 2011). Racial and ethnic identity models have shown to be useful when providing counseling services to Latino clients (Delgado-Romero, 2001), yet participants did not discuss the use of these models while being interviewed. Strong ethnic identities are protective factors for Latinos, particularly as they feel more positive about their ethnicity (Telzer \& Garcia).

Although participants clearly identified the unique needs of undocumented Latino students, there was a sound emphasis on treating all students the same when conducting counseling services. The grounded theory that emerged from this study was that these participants supported pragmatic equality when working with undocumented Latino youth on career issues. This pragmatic equality refers to the reported school counseling and career guidance practices with undocumented Latino youth among this sample of participants. Sadly, due to the political climate surrounding the issue of immigration, equal opportunities are not a reality when it comes to career options for undocumented Latinos. Thus, the call to increase the participation, training and responsibility for school counselors to advocate for this marginalized group of students remains at an all-time high.

The use of counseling approaches that best fit the population of need must be central for counseling to be effective. Career assessments do not take into consideration student values related to ethnicity or familial commitments (Ortiz \& Hinojosa, 2010), and are not normed for undocumented Latino students. Hence, the use of these assessments is not appropriate and do not meet the unique career counseling needs of undocumented Latino youth. Several participants hosted career fairs and some intentionally recruited members of the Latino population to serve as role models, which align with the best practices recommended by Villalba (2007). The use of multicultural career counseling theories was not mentioned throughout participant interviews and due to the minimal reference to the use of career counseling theories in general, it appears unlikely that participants intentionally infused any multicultural career counseling theories into their practice. 
Providing hope was shown to be a difficult challenge for participants, particularly when wanting to provide a positive career outlook for undocumented Latino students. There was a strong desire to do more for students, but several participants struggled with where to begin. Many participants reported feeling hopeless because they did not have the ability to relieve the external barriers that continue to oppress undocumented Latino youth who desire successful careers in the U.S. Taking time to understand the elements of the counseling relationship (Lambert, 1992; Wampold, 2001) appeared to facilitate therapeutic interventions. Most participants continued to provide hope to undocumented Latino students by encouraging them to look for opportunities to obtain citizenship.

As a result of this study, this author notably highlights three salient observations related to the study aims that can be considered important unforeseen findings. First, although it was not originally a major focus of this study, this author acknowledges that various levels of cultural identity development may have impacted participants' worldview and responses in their respective interviews. Secondly, this researcher observed that despite participants reporting equal treatment to undocumented Latino youth, this equal treatment may have ultimately created inequitable services potentially causing more harm to this already marginalized group. Lastly, this author observed that those participants that did not embrace an advocacy stance in working undocumented Latino youth may have essentially denied equal access to them. Although these observations were unforeseen when beginning this research, they were important to include in this discussion to help improve active participation, training, and responsibility of school counselors on behalf of undocumented Latino students.

\section{Implications and Recommendations}

\section{Advocacy Implications and Recommendations for School Counselors}

The foundation of the ASCA National Model (2005) includes the qualities of leadership, advocacy, and collaboration, which are envisioned to create system change on multiple levels. As school counselors continue to be charged with cultivating the career development of all students, they must continue their participation and training in advocacy efforts. It appeared that school counselors in this sample were not adequately prepared to offer career counseling for a variety of reasons. Although their education and training included competencies embracing cultural sensitivity, they failed to use normed referenced assessments and theoretically based career counseling interventions and techniques. These participants were unable to provide equal services to undocumented Latino students in comparison to services provided to students who had citizenship and spoke native English. School counselors need to understand the significance of applying social justice theory to practice, specifically with undocumented Latino youth. School counselors need continuous advocacy training and need to take responsibility for seeking knowledge that will benefit their students. This includes the essential need to recruit bilingual counselors (Villalba, 2007) to meet the needs of the changing demographics in our society. School counselors must also participate and gain education on the cultural experiences of undocumented Latinos and knowledge on current immigration acts 
such as DACA, to facilitate advocacy efforts which impact students' futures.

Conducting career counseling the same way to very different populations fails to consider the complexity of the unique challenges and barriers faced by undocumented Latino youth. There is potential harm endured by students who encounter school counselors who perpetuate or (un)intentionally behave in ways that don't challenge inequitable systems. Hence, school counselors who are multiculturally incompetent or those who do not embrace an advocacy identity, may bring very real and disastrous consequences for students. For school counselors to advocate for the futures of undocumented youth, unique interventions are warranted. The use of the Collaborative Social Justice Model (CSJM) for School Counselors and Student Affairs Professionals is a framework in which school counselors can provide unique collaborative action steps to advocate for undocumented Latino youth within the classroom, among change agents, through academic policies within K-16 institutions, and within the cultural values of the school (Storlie \& Jach, 2012). This also includes the recommendation of community college options, which often do not require Social Security numbers and are less expensive than four-year institutions. Suggestions and action steps include hosting multicultural trainings, working with school personnel on anti-bullying campaigns, identifying pathways for citizenship, infusing outreach, connecting with neighboring schools, the development of mentoring programs, and supporting social justice initiatives at the state and federal level (Storlie \& Jach, 2012).

School counselors often provide specialized groups (groups for girls, groups targeted for students with low academic achievement scores, etc.) and it is reasonable that providing a career counseling group to address the unique needs of undocumented Latino students would be of great benefit. The use of a group format among these participants appeared to generate the significant success in outcomes of meeting the needs of undocumented Latino students and is also supported in counseling literature (Chen et al., 2010). Moreover, best practice training can also include elements outlined by organizations such as ASCA, Educators for Fair Consideration, the National Immigration Law Center, and United We Dream.

\section{Advocacy Implications and Recommendations for School Counselor Education}

Advocacy in teaching and supervision. There is an inadequacy in the training that is provided to professional school counselors on issues affecting undocumented Latino students in the U.S. Counselor educators need to educate themselves about this population and improve and enhance their curriculum in order to produce culturally competent professional school counselors. Exploration of the utilization of multicultural career counseling theories outside of the classroom must be also addressed. "Theory to practice" must be modeled by counselor educators and examples addressing this can be conducted in both didactic and experiential courses, such as practicum and internship. Counselor educators also have the responsibility in providing advanced workshops to current counseling professionals in the community in order to meet the unique needs of undocumented Latino students. 
In order to infuse the advocacy identity of school counselors (and all counselors), counselor educators can infuse Advocacy Competencies (Lewis, Arnold, House, \& Toporek, 2003) into curriculum, to establish the importance of social justice and advocacy on student/client level, the school/community level and in the public domain. This requires participation of students and educators to embrace the identity of advocate and to take strong steps in supporting marginalized groups. Infusing the School Counselor Social Justice Training Checklist for School Counseling Programs (Singh, Urbano, Haston, \& McMahon, 2010) may also assist counseling programs in teaching social justice strategies to counselors in training. Additionally, counselor educators have the opportunity to explore advocacy and policy at the state legislative level for the training of school counselors. Providing opportunities for discussion on this topic, infusing service learning projects into syllabi and providing practicum and internship opportunities with undocumented Latino students would enhance multicultural competency, awareness and preparedness among counselors in training. These skills would be transferable to other undocumented or historically marginalized populations.

As supervisors, counselor educators often take on the role of counselor, teacher, evaluator and consultant (Bernard \& Goodyear, 2009) with counselors in training. As such, school counselor educators will need to stay up to date on legislative acts affecting undocumented Latino students in order to provide accurate information during supervision sessions for those counselors in training working with this population. Counselor educators may also choose to incorporate a social justice philosophy (Lee, 2012) during their supervision sessions to shed light on advocacy through counseling practice. Finally, supervisors need to assess for potential signs of vicarious trauma (Trippany, Kress \& Wilcoxin, 2004) in supervisees due to the traumatic experiences by many undocumented Latino students.

Advocacy Research. Results of this research provide multiple opportunities for counselor educators and researchers to explore gaps in the counseling literature in working with undocumented Latino students. Exploration of the reasons why multicultural career counseling theories are not utilized among school counselors would provide insights unexamined in counseling literature. Research studies with additional advocacy components could also include norming various career assessments for undocumented Latino students, along with investigation of further challenges of undocumented Latino students with disabilities, or those with a different sexual orientation from the majority population. Quantitative studies assessing the perceived effectiveness of school counseling and clinical mental health services provided to undocumented Latino students would provide a picture of how the counseling profession can better serve this population. Research specifically investigating the career counseling methods which school counselors in border cities use with undocumented Latino students may also provide an alternative lens to this topic due to the influence of border pedagogy (Romo, 2005). Due to the sociocultural environment of undocumented Latino youth and the violent stories of migration to the U.S., exploring research on vicarious trauma (Trippany et al., 2004) among counselors and counselors in training is needed.

\section{Limitations}


With a qualitative research design, the researcher is the human instrument and may lack objectivity to the study. In response to this limitation, this author utilized two peer reviewers, utilized a reflective journal after completion of the interviews and received extended supervision by a seasoned, qualitative multicultural researcher. With qualitative research, there is often a need for observational onsite data to be collected (Patton, 2002). With this participant sample, access to work environments for the collection of observational data collection was not available. Additionally, only six states were represented of the ten most highly populated with undocumented Latino immigrants and very few came from border states. Despite vigorous recruitment, participants were not obtained from Georgia, New York, New Jersey or Arizona. Additionally, three interviews were conducted via email by request of the participants. Although this allowed for follow up questions to be asked via email, I was limited in having the ability to ask follow up questions in the moment. A threat to trustworthiness was also a limitation to this study in that participants may have been bias in their responses to interview questions (Bowen, 2005) or may be subject to influences of social desirability.

\section{Conclusions}

Using a grounded theory methodology, insights were gained on how school counselors work on issues of career development with this marginalized population. Results offered a unique perspective in which school counselors can be trained on realistic and empowering methods that foster career development in undocumented Latino youth. This study helps to close the gap in counseling literature on the unique experiences of school counselors working with undocumented Latino youth in school settings, particularly on the issues of career development. As a result of this research, there is a greater understanding of the challenges and barriers that these participants underwent when working with this marginalized population. There has been a voice given to the difficulties school counselors have in effectively providing career counseling services to undocumented Latino students. Comprehensive advocacy practices are still needed to help school counselors, and clinical mental health counselors, to effectively work with this population on areas of career counseling, particularly during the current political climate where division and controversy looms over immigration issues. With the paucity of school counseling research on this topic, further research efforts to provide best practices in working with undocumented Latino youth is strongly recommended.

\section{Author Contact Information}

Correspondence regarding this article should be directed to: Cassandra A. Storlie, Counselor Education \& Supervision, Kent State University, Kent, Ohio 44240. E-mail: cstorlie@kent.edu

Dr. Storlie earned her Ph.D. in Counselor Education and Supervision from the University of lowa and is an assistant professor at Kent State University in the Counselor Education and Supervision program. She was awarded the National Career Development Association's Diversity Initiative Award and was recognized as Kent State University's Scholar of the Month in January of 2016. As a Latina, she is focused on social justice and advocacy efforts to support culturally responsive, evidenced based practices in college and career readiness. 


\section{References}

Abrego, L., \& Gonzales, R. (2010). Blocked paths, uncertain futures: The postsecondary education and labor market prospects of undocumented Latino youth. Journal of Education for Students Placed at Risk, 15, 144-157. doi: 10.1080/10824661003635168.

American School Counselor Association. (2005). The ASCA national model: A framework for school counseling programs (2nd ed.). Alexandria, VA: Author.

American School Counselor Association (2014). The role of the professional school counselor. Retrieved from http://www.schoolcounselor.org/asca/media/asca/home/RoleStatement.pdf

Arrendondo, P., Gallardo-Cooper, M., Delgado-Romero, E.A., \& Zapata, A.L. (2014). Culturally responsive counseling with Latinas/os. Alexandria, VA: American Counseling Association.

Bernard, J. M., \& Goodyear, R. K. (2009). Fundamentals of clinical supervision, 4th edition. Columbus, OH: Merrill.

Bowen, G. A. (2005). Preparing a qualitative research based dissertation: Lessons learned. The Qualitative Report, 10 (2), 208-222.

Casas, J. M., \& Cabrera, A. P. (2011). Latino/a Immigration: Actions and outcomes based on perceptions and emotions or facts. Hispanic Journal of Behavioral Sciences, 33, 283-303. doi: $10.1177 / 0739986311416342$

Chen, E., Budianto, L., \& Wong, K. (2010). Professional school counselors as social justice advocates for undocumented immigrant students in group work. The Journal for Specialists in Group Work, 35 (3), 255-261. doi: 10.1080/01933922.2010.492897

Constantine, M., Erickson, C., Banks, R., \& Timberlake, T. (1998). Challenges to the career development of urban racial and ethnic minority youth: Implications for vocational intervention. Journal of Multicultural Counseling and Development, 26 (2), 82-94.

Corbin, J. \& Strauss, A. (2008). Basics of qualitative research: Techniques and procedures for developing grounded theory (3rd ed). Thousand Oaks, CA: Sage Publications.

Delgado-Romero, E. A. (2001). Counseling a Hispanic/Latino client - Mr. X. Journal of Mental Health Counseling, 23 (3), 207-221.

Dotson-Blake, K., Foster, V., \& Gressard, C. (2009). Ending the silence of the Mexican immigrant voice in public education: Creating culturally inclusive family-school community partnerships. Professional School Counseling, 12 (3), 230-239.

Drachman, E. (2006). Access to higher education for undocumented students. Peace Review: A Journal of Social Justice, 18, 91-100. doi: 10.1080/10402650500511667.

Dream Act Portal. (2012). The DREAM Act. Retrieved from: http://dreamact.info/ 
Drew, C. J., Hardman, M. L., \& Hosp, J. L. (2008). Designing and conducting research in education. Thousand Oaks, CA: Sage.

Educators for Fair Consideration. (2012). Fact sheet: An overview of college bound undocumented students. Retrieved from: http://e4fc.org/images/Fact_Sheet.pdf

Gildersleeve, R., Rumann, C., \& Mondragon, R. (2010). Serving undocumented students: Current law and policy. New Directions for Student Services, 131, 5-18. doi:10.1002/ss.364.

Griffin, D., \& Steen, S. (2011). A social justice approach to school counseling. Journal for Social Action in Counseling and Psychology, 3 (1), 74-85. Retrieved from http://www.psysr.org/jsacp/griffinv3n1-11_74-85.pdf

Gonzales, R. (2009, April). Young lives on hold: The college dreams of undocumented students. Retrieved from http://professionals.collegeboard.com/profdownload/young-lives-onholdcollege-board.pdf

Gonzales, R. (2010). On the wrong side of the tracks: Understanding the effects of school structure and social capital in the educational pursuits of undocumented immigrant students. Peabody Journal of Education, 85, 469-485. doi: 10.1080/0161956X.2010.518039

Gonzales, R. (2011). Learning to be illegal: Undocumented youth and shifting legal contexts in the transition to adulthood. American Sociological Review, 76, 602-619. doi: $10.1177 / 0003122411411901$

Guyll, M., Madon, S., Prieto, L., \& Scherr, K. C. (2010). The potential roles of self fulfilling prophecies, stigma consciousness, and stereotype threat in linking Latino ethnicity and educational outcomes. Journal of Social Issues, 66 (1), 113-130.

Harley, D., Jolivette, K., McCormick, K., \& Tice, K. (2002). Race, class and gender: A constellation of "Positionalities" with implications for counseling. Journal of Multicultural Counseling and Development, 30 (4), 216-238.

Henry, C. S., Merten, M. J., Plunkett, S. W., \& Sands, T. (2008). Neighborhood, parenting, and adolescent factors and academic achievement in Latino adolescents from immigrant families. Family Relations, 57, 579-590.

Jefferies, J. (2008). Adolescent literacy policy; Do undocumented students play by the rules? Journal of Adolescent \& Adult Literacy, 52 (3), 249-251. doi: 10.1598/JAAL.52.3.8.

Lee, C. C. (2012). Social justice as the fifth force in counseling. In C.Y. Chang, C. A. Barrio-Minton, A. L. Dixon, J. E. Myers \& T. J. Sweeney (Eds.), Professional counseling excellence through leadership and advocacy. New York, NY: Routledge.

Lewis, J., Arnold, M. S., House, R., \& Toporek, R. (2003). Advocacy competencies [Electronic version]. Retrieved February 24, 2013, from http://www.counseling.org/Publications 
Myhill, W. N. (2004). The state of public education and the needs of English language learners in the era of 'No child left behind'. Journal of Gender, Race and Justice, 8, 393-447.

National Board for Professional Teaching Standards. (2002). School counseling standards. Retrieved from: http://www.nbpts.org/userfiles/File/ecya_sc_standards.pdf

Oldfield, K. (2007). Humble and hopeful: Welcoming first generation poor and working class students to college. About College, 11 (6), 2-12. doi: 10.1002/abc.188

Ortiz, A., \& Hinojosa, A. (2010). Tenuous options: The career development process for undocumented students. New Directions for Student Services, 131, 53-65. doi:10.1002/ss.367.

Passel, J. (2006). The size and characteristics of the unauthorized migration population in the U.S.: Estimates based on the March 2005 current population survey. Washington, D.C.: Pew Hispanic Center.

Passel, J., \& Cohn, D. (2011). Unauthorized immigrant population: National and state trends. Washington, D.C.: Pew Hispanic Center. Retrieved from: http://www.pewhispanic.org/2011/02/01/unauthorized-immigrant-populationbrnationaland-state-trends-2010/

Patton, M. Q. (2002). Qualitative research and evaluation methods (3rd ed.). Thousand Oaks, CA: Sage Publications.

Perez, W., Espinoza, R., Ramos, K., Coronado, H., \& Cortes, R. (2009). Academic resilience among undocumented Latino students. Hispanic Journal of Behavioral Sciences, 31 (2), 149-181. doi: 10.1177/0739986309333020.

Romo, J. (2005). Border pedagogy from the inside out: An autoethnographic study. Journal of Latinos and Education, 4 (3), 193-210.

Santiago-Rivera, A. L., Arredondo, P., \& Gallard-Cooper, M. (2002). Counseling Latinos and la familia: Multicultural aspects of counseling and psychotherapy. Thousand Oaks, CA: Sage.

Singh, A. A., Urbano, A., Haston, M., McMahon, E. (2010). School counselors strategies for social justice change: A grounded theory of what works in the real world. Professional School Counseling, 13, 135-145.

Sox, A. K. (2009). Latino immigrant students in southern schools: What we know and still need to learn. Theory into Practice, 48, 312-318. doi: 10.1080/00405840903192912

Smith-Adcock, S., Daniels, M. H., Lee, S. M., Villalba, J. A., \& Indelicato, N. A. (2006). Culturally responsive school counseling for Hispanic/Latino students and families: The need for bilingual school counselors. Professional School Counseling, 10 (1), 92-101. 
Storlie, C. A. (2015). Revisiting career challenges and reviving hope while career counseling undocumented Latino youth. Career Convergence. Retrieved from: http://associationdatabase.com/aws/NCDA/pt/sd/news_article/110891/_PARENT/CC_layout_ details/false

Storlie, C. A., \& Jach, E. A. (2012). Social justice collaboration in schools: A model for working with undocumented Latino students. Journal for Social Action in Counseling and Psychology, 4, 99116. Retrieved from http://www.psysr.org/jsacp/Storlie-v4n2-12_99-116.pdf

Telzer, E. H. \& Garcia, H. A. (2009). Skin color and self perceptions of immigrant and U.S. born Latinas: The moderating role of racial socialization and ethnic identity. Hispanic Journal of Behavioral Sciences, 31, 357-374. doi: 10.1177/0739986309336913

Trippany, R. L., Kress, V. E., \& Wilcoxon, S. A. (2004). Preventing vicarious trauma: What counselors should know when working with trauma survivors. Journal of Counseling and Development, 82, 31-37.

United States Citizenship and Immigration Services. (2014). Executive actions on immigration. Retrieved from: http://www.uscis.gov/immigrationaction

Villalba, J. A. (2007). Culture specific assets to consider when counseling Latina/o children and adolescents. Journal of Multicultural Counseling and Development, 35, 15-25.

Wampold, B. (2001). The great psychotherapy debate: Models, methods, and findings. New Jersey: Lawrence Erlbaum Associates. 